\title{
PRODUCTION OF EXTRACELLULAR PIGMENT FROM MICROBES AND ITS APPLICATION
}

\author{
V.Navin raju, T.Radha. \\ Department of Biochemistry, KonguArts and Science College, Erode, Tamilnadu.
}

\begin{abstract}
-
Vegetable sample procured from local markets of Tamil Nadu were used in this study to isolate pigments producing bacteria. Red pigment bacteria were isolated and developed into nutrient media. Morphological observations revealed that the isolated bacteria are Gram Negative, cocci and biochemical characterization was carried out and isolated are identified as Rhodotorula sp. Maximum production of pigments was observed at $35^{\circ} \mathrm{C}$ and $\mathrm{pH}$ 7. Pigment was extracted from the isolated microorganism and it was dried and powdered. Extracted pigment was check for the microbial action and it was used to dyeing the cloth.
\end{abstract}

Key words : Biocolours, Bacteria, Microbial action, Dyeing.

\section{INTRODUCTION}

Natural colours are generally extracted from fruits, vegetables, roots and microorganisms and are often called "biocolours" because of their biological origin ( Pattnaik et al.., 1997).

Heath environmental concerns due to unmonitored utilization of synthetic colorants revived interest in natural dyes as they are safer, healthier, biodegradable, and exhibit higher compatibility with the environment ( Fatima shatila et al.., 2013 )

Many artificial synthetic colorants are widely used in food stuff, dye, cosmetic and pharmaceutical manufacturing processes. The synthetic pigments which are used produce harmful effect to human and pollute water and soil. In textile industry during manufacturing and usage approximately $10-15 \%$ of the dye is lost directly to wastewater and pollute the environment ( Palanivel velmurugan et al.., 2009 ).

Natural pigments can be obtained from two major sources namely plants and microorganisms. The accessible authorized natural pigments from plants have numerous drawbacks such as instability against light, heat, or adverse $\mathrm{pH}$ and low water solubility.

The advantage of pigment production from microorganisms include easy and fast growth in the cheap culture media. Microoganisms produce various pigment like carotenoids, melanins, flavones, quinines. The various types of microorganisms like bacteria, fungi, algae, yeast are present in different colours. The coloured microorganisms are isolated from various samples and pigment was extracted from the microorganisms and it used for industry ( Sahara sayeed khan et al.., 2013 ).

Different pigmented microorganisms were isolated from the vegetable effects on temperature and $\mathrm{pH}$ for pigment production was identified. The particular strain was identified by using different biochemical test. Hence microbial pigment production is one of the emerging fields of research to demonstrate its potential for various industrial application.

There is an increasing demand for natural colour in the food, pharmaceutical, cosmetics, textile, printing and dye industry.

\section{MATERIALS AND METHODS}

\section{Collection of Samples:}

Vegetable (beetroot) sample was collected from local market in Erode, Tamil Nadu, India.

\section{Sample preparation:}

$1 \mathrm{gm}$ of vegetable (beetroot) was mashed with $10 \mathrm{ml}$ of distilled water and it was used.

\section{Isolation and screening of pigmented microorganisms:}

The sample was serially diluted up to $10^{-3}$ and 0.1 $\mathrm{ml}$ of the diluted sample was spread on nutrient agar plate. Incubated for $24 \mathrm{hrs}$ at $30^{\circ} \mathrm{C}$ and it was checked for 
the pigmented production. The pigment produced colonies were used for the future studies.

\section{Purification of cultures}

Pigmented Bacterial isolates was purified by streaking onto nutrient agar plate and it was incubated for $24 \mathrm{hrs}$ at $30^{\circ} \mathrm{C}$.

\section{Maintenance of culture}

Pigmented Bacterial cultures were grown on nutrient agar and it was maintained at $2-4^{\circ} \mathrm{C}$ temperature in refrigerator and sub cultured into respective medium.

\section{Characterization of isolated pigmented microorganisms:}

\section{Gram stain:}

The stain makes use of the differing membrane structures between Gram positive (single cell membrane with a tough outer cell wall of peptidoglycan), and Gram negative organisms (have two layers of membranes, with a thin layer of peptidoglycan sandwiched between them).

Prepare a bacterial smear and heat fixed on a slide, pour a few drops of crystal violet on a smear waite for 1 minute and wash with water. Now fixed the smear with Gram's iodine for 1 minute and wash again with water and decolourize the stain with 95\% ethyl alcohol dropwise, wash with water and conter stain with safranine ( $45 \mathrm{sec}$ ) and again wash with water. After drying examine under oil immersion.

Various Biochemical test which was performed as listed below:

\section{Indole test:}

Used to determine the ability of an organism to split indole from the amino acid tryptophan using the enzyme tryptophanase. Red layer formed on surface of the media showed Positive result and yellow layer showed negative result.

\section{Methyl Red Test}

It is used to determine the ability of an organism to produce mixed acid end products from glucose fermentations. Some organisms produce large amounts of various acids (lactic, acetic, succinic, formic) plus $\mathrm{H} 2$ and $\mathrm{CO}$. The large amounts of acids lower the $\mathrm{pH}$ to lower than 5.0. These organisms also produce great amounts of gas due to the presence of the enzyme formic hydrogenlyase. Red color developed indicates Positive result and yellow color developed indicates Negative result.

\section{Voges- Proskauer Test}

It is used to determine the ability of an organism to produce acetoin; 2,3 butanediol; and ethanol which causes lowering of the $\mathrm{pH}$ than the methyl red positive organisms. VP test detects the presence of acetoin, which is a precursor to 2,3 butanediol.

\section{Citrate Utilization}

It is used to determine if an organism is capable of using citrate as the sole source of carbon with production of the enzyme citratase. The media contains sodium citrate as the carbon source, and ammonium salts as the nitrogen source, with bromothymol blue as the $\mathrm{pH}$ indicator. An organism that uses citrate breaks down the ammonium salts to ammonia, which creates an alkaline $\mathrm{pH}$. Alkaline $\mathrm{pH}$ causes media to change from green to Prussian blue shows positive result and no color change in the medium denotes negative result.

\section{Catalase Test}

It is used to test for the presence of enzyme catalase. Hydrogen peroxide $\left(\mathrm{H}_{2} \mathrm{O}_{2}\right)$ is formed as an end product of the aerobic breakdown of sugars. When $\mathrm{H}_{2} \mathrm{O}_{2}$ accumulates, it becomes toxic to the organism. Catalase decomposes $\mathrm{H}_{2} \mathrm{O}_{2}$ and enables the organism to survive. Only obligate anaerobes lack this enzyme. Bubbling (O2 gas is liberated from the $\mathrm{H} 2 \mathrm{O} 2$ ) shows positive result and no bubbling denotes negative result.

\section{Nitrate Reductase Test}

It is used to determine the ability of an organism to reduce nitrate $\left(\mathrm{NO}_{3}\right)$ to nitrite $\left(\mathrm{NO}_{2}\right)$ or nitrogen gas $\left(\mathrm{N}_{2}\right)$ by the production of the enzyme nitratase. The reduction of nitrate to nitrite or nitrogen gas takes place under anaerobic conditions in which an organism derives its oxygen from nitrate. Appearance of red color denotes that nitrate is reduced to nitrite and it is a positive result. If there is no color change the confirmation test was done by adding a small pinch of zinc powder.

\section{Urease Test}

Used to determine the ability of an organism to split urea to form ammonia (an alkaline end product) by the action of the enzyme urease. Media also contains the $\mathrm{pH}$ 
indicator phenol red, which turns an intense pink at alkaline $\mathrm{pH}$. Intense pink/red color indicates positive result and no color change denotes negative result.

\section{Triple sugar iron agar test (TSI)}

This test is specifically used for the identification of enteric bacteria, but can also be used for other organisms. This agar contained $0.1 \%$ glucose, $1.0 \%$ lactose, and $1.0 \%$ sucrose in one tube. Along with the three sugars, phenol red was also present to verify if fermentation occurred.

\section{Lipid hydrolysis}

It is used to determine the ability of an organism to produce the enzyme lipase which hydrolyzes fat. Lipase splits fats into glycerol and fatty acids that can be used for anabolism or energy production.

\section{Extraction of pigments}

Different solvents like ethyl acetate, methanol, acetone, hexane was used to check for the maximum solubility of pigments. And the solvent was selected by checking the maximum solubility of pigment in it. After incubation the bacterial cells were washed with methanol and it was transferred to centrifuge tube. The tube was centrifuged at $5000 \mathrm{rpm}$ for 15 minutes. The colored supernatant and pellet was separated. The colored supernatant was used directly and pellet was transferred to evaporating dish for one day and kept at room temperature.

\section{RESULTS AND DISCUSSION}

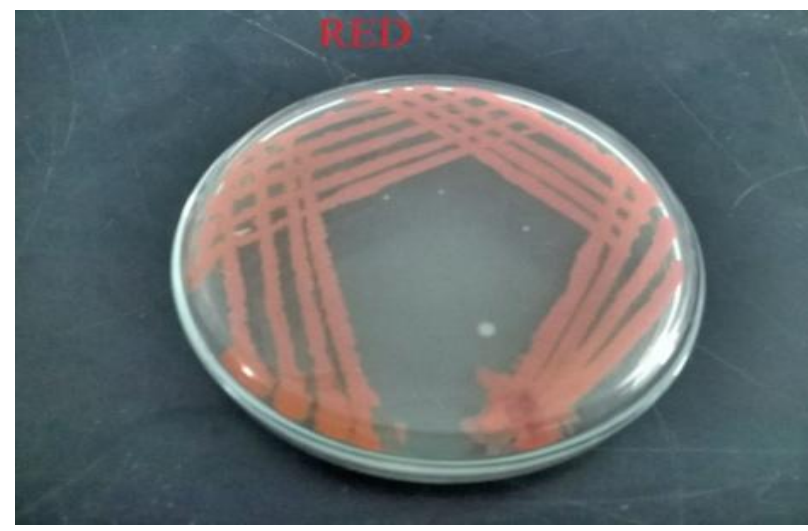

Fig.1. Isolation of pigmented microorganism from sample

From the vegetable (beetroot) extract, one pigmented microorganism was isolated.

\section{Effect of different pH \& Temperature on the pigment color}

Selection of $\mathrm{pH} \&$ temperature for pigment producing microorganisms.

Table 1 Red pigment microorganism was terated with different $\mathrm{pH}$ \& Temperature

\begin{tabular}{|c|c|c|c|c|}
\hline Colour & $\mathrm{pH}$ & $\begin{array}{c}\text { Colour } \\
\text { change }\end{array}$ & $\begin{array}{c}\text { Temperature } \\
{ }^{\circ} \mathrm{C}\end{array}$ & $\begin{array}{c}\text { Colour } \\
\text { change }\end{array}$ \\
\hline \multirow{6}{*}{ RED } & 2 & Light pink & 25 & No \\
\cline { 2 - 5 } & 4 & Light pink & 40 & No \\
\cline { 2 - 5 } & 7 & Red & 55 & No \\
\cline { 2 - 5 } & 8 & Violet & 60 & No \\
\cline { 2 - 5 } & 10 & Violet & Above 60 & Pink \\
\cline { 2 - 5 } & & & & \\
\hline
\end{tabular}

When the Red pigment producing colonies are treated with different $\mathrm{pH}$, different coloured pigments are produced. Table 1 shows the various colours produced when $\mathrm{pH}$ \& Temperature is changed ( Ahmad et al., 2012 ). When the temperature is changed from $25^{\circ} \mathrm{C}$ to $60^{\circ} \mathrm{C}$ there was no change but above $60^{\circ} \mathrm{C}$ the Red colour colonies were changed to pink colony.

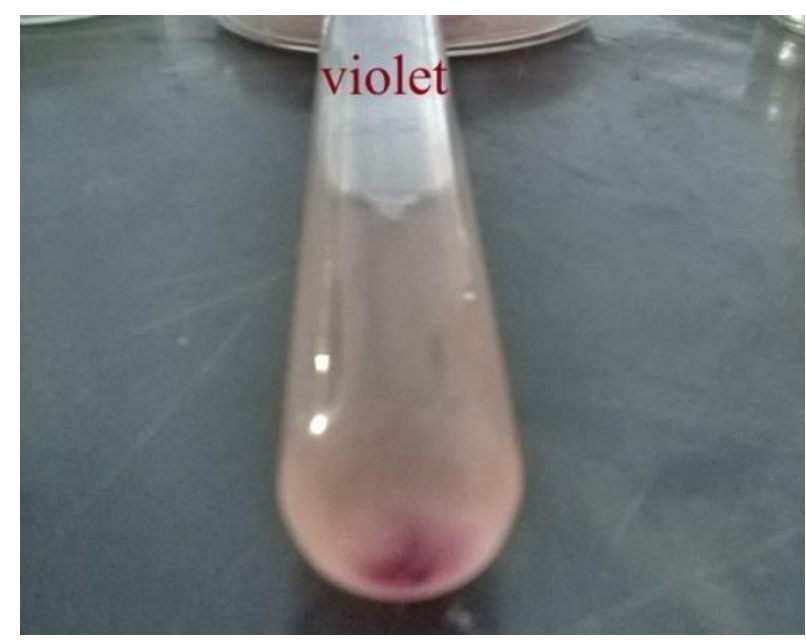

Fig.2Violet colour microorganism ( $\mathrm{pH} \& 10$ ) 


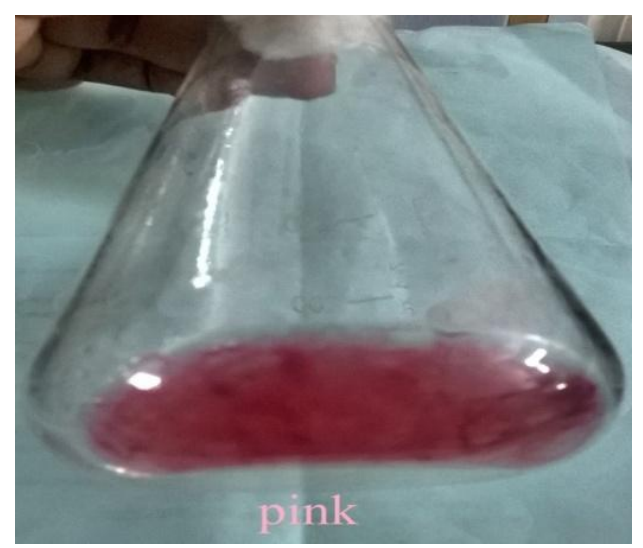

Fig.3 Pink color microorganism ( Tem: above $60^{\circ} \mathrm{C}$ )

\section{Biochemical test results}

The biochemical results for the Red pigmented microorganism was shown in the following Table 2. The table shows that the Red pigment producing microorganism can split indole \& can produce mixed acid end products from glucose fermentations with production of citrate, catalase, nitrate reductase \& urease enzymes, TSI test shows that this organism can ferment glucose only. These organism can also hydrolyse lipids
Table 2.. Biochemical characterization of microorganism

\begin{tabular}{|c|c|}
\hline Biochemical Test & Red \\
\hline Indole & Positive \\
\hline Methyl red & Positive \\
\hline Voges Proskauer & Positive \\
\hline Citrate & Positive \\
\hline Catalase & Positive \\
\hline Nitarate reductase & Positive \\
\hline Urease & Positive \\
\hline TSI Test & Glucose \\
\hline Lipid hydrolysis & Positive \\
\hline
\end{tabular}

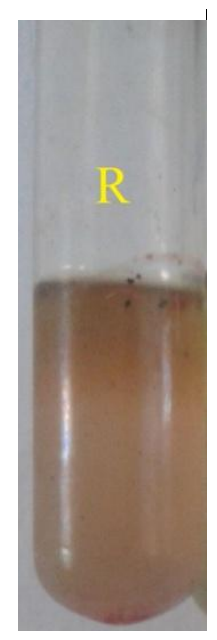

Fig4.Indole test

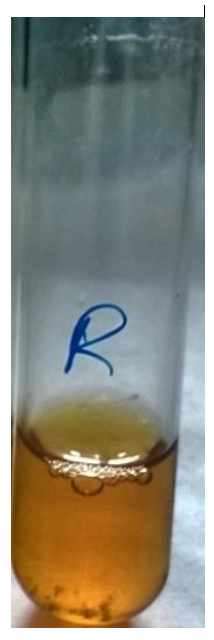

Voges- Proskauer Test

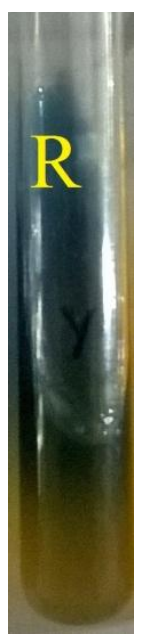

Citrate Utilization

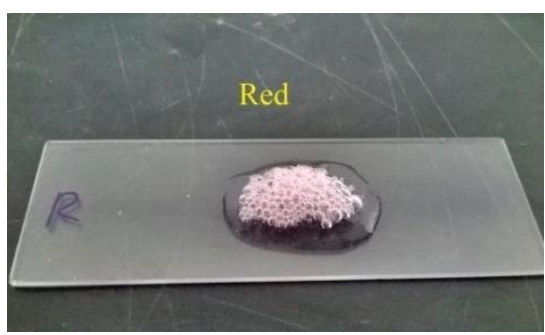

Catalase Test 


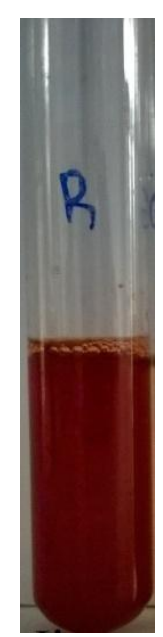

Fig5.Nitrate Reductase Test

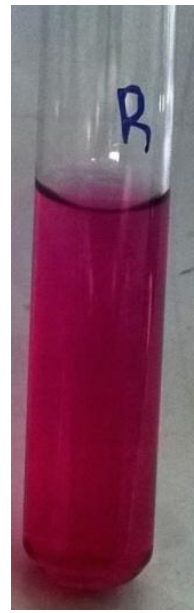

Urease Test

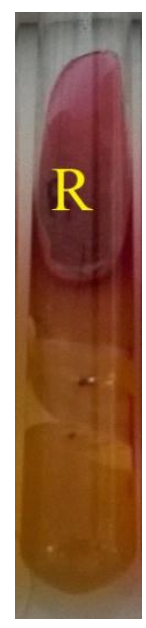

Triple sugar iron agar test

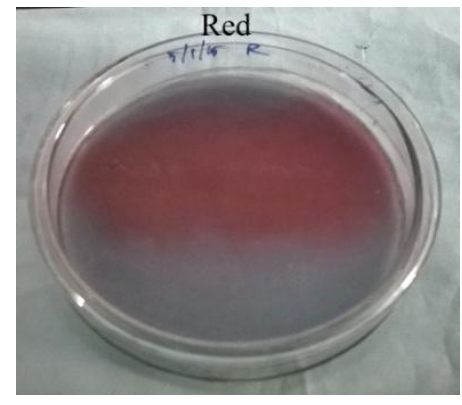

Lipid hydrolysis

\section{Extraction and drying of pigment}

Pigments were extracted from the isolated microorganisms. Methanol was used for the pigment extraction and the extracted pigment was dried and it was powdered.

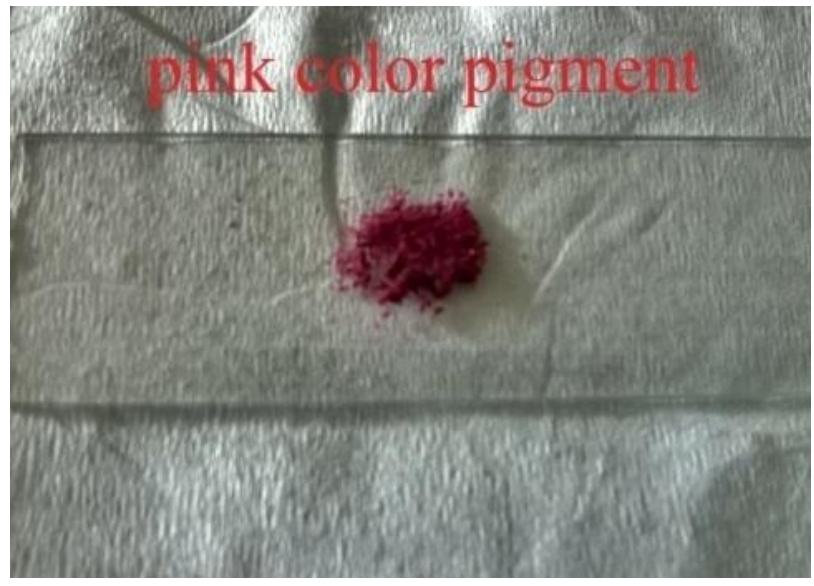

Fig.6.Microbial action of extracted pigments

Pigments that are isolated from the microorganisms was checked for the microbial action. Extracted pigment was streaked on to the nutrient agar plate and it was incubated at $30^{\circ} \mathrm{C}$ for $24 \mathrm{hrs}$. After incubation there was no microbial growth.

Extracted extracellular pigment was used for dyeing the cloth. These microbial pigments can also used for coloring candles, paper, soap, pencil, and high lighter pen.

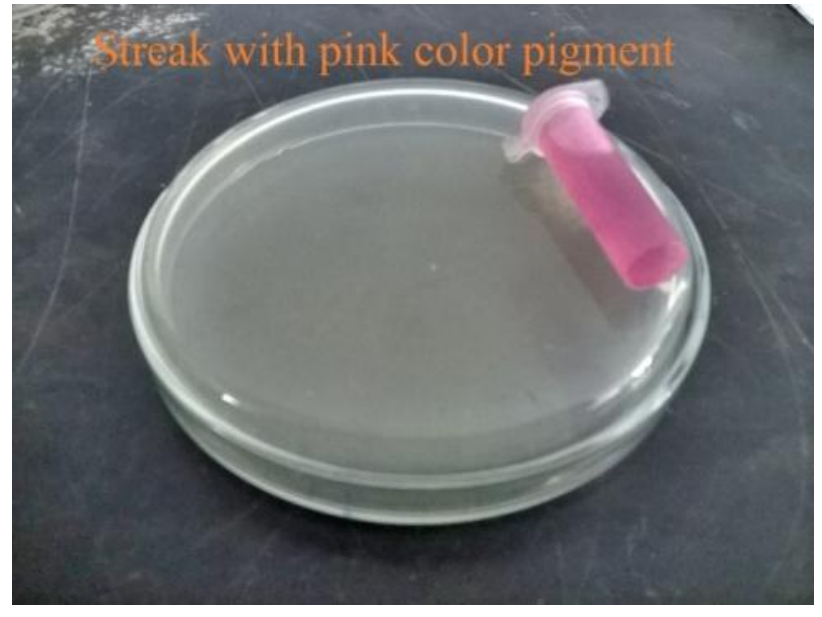

Fig7.Application of extracted pigment

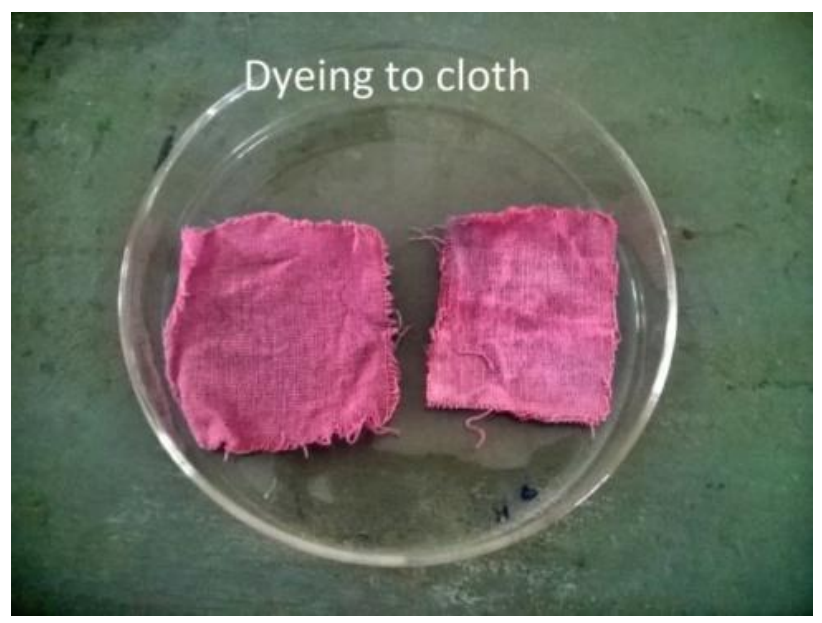

Fig8.Identification of microorganisms

Microorganisms were identified using known microorganisms. 
Table 3 Comparison of Red colour microorganism test result with Rhodotorula sp. test result.

\begin{tabular}{|c|c|c|}
\hline Biochemical Test & Red microorganism & Rhodotorula sp. \\
\hline Gram's staining & Negative & Negative \\
\hline Indole Test & positive & positive \\
\hline Methyl Red Test & positive & positive \\
\hline $\begin{array}{c}\text { Voges-Proskauer } \\
\text { Test }\end{array}$ & positive & positive \\
\hline Citrate Test & positive & positive \\
\hline Catalase Test & positive & positive \\
\hline Urease Test & positive & positive \\
\hline Nitrate reductase & positive & positive \\
Test & & Glucose \\
\hline Triple Sugar lon \\
Test
\end{tabular}

From the table it is concluded that the microorganism which was isolated from vegetable sample is identified as Rhodotorula sp. which produced Red coloured pigment.

\section{CONCLUSION}

Colorants are used in a vast majority industries from clothing and textiles. Most of the synthetic colorants are harmful to the environment and are difficult to biodegrade. There is an increasing interest involving microorganisms as an alternate source of synthetic colorants. In this consideration the present study was carried out to reduce the effects of non biodegradable pollutants. In the above study soil was used for isolating microorganisms. The pigment ( Red ) producing microorganisms are isolated from the source and their pigment production was increased in the nutrient medium at $\mathrm{pH} 7$ at $30^{\circ} \mathrm{C}$. This indicates that pigment production in influenced by physical factors like temperature \& $\mathrm{pH}$ of the culture medium. The biochemical characterization for the Red pigment producing microorganism showed positive result and strain characterization revealed that it is small, circular and gram negative bacteria and this was compared with the known species Rhodotorula which resembled similar. The pigments produced were extracted with methanol and were tested for the presence of microbes in the pigments. The extracted pigment was applied for dyeing fabric. The results showed that the fabric can uptake the dye after $24 \mathrm{hrs}$ of soaking. In future the present study can be implemented to replace the synthetic colorants used in textile and dying industries. This aims to reduce the toxic effects of synthetic colorants in aquatic ecosystems.

\section{ACKNOWLEDGEMENT}

I wish to thank our Institution of Kongu Arts and Science College, Erode for providing the necessary facilities for this study.

\section{REFERENCES}

[1] Fatima Shatila, Hoda Yusef and Hanafy Holail, 2013. Pigment production by Exiguobacterium aurantiacum $\mathrm{FH}$, a novel Lebanese strain. International journal of current Microbiology and Applied science, vol.2, pp. 176-191.

[2] Palanivel Velmurugan, Seralathan Kamala-Kannan, Vellingiri Balachandar b,Perumalsamy Lakshmanaperumalsamy, 2009. Natural pigment extraction from five filamentous fungi for industrial applications and dyeing of leather. Carbohydrate Polymers, pp 1-7.

[3] Kamla Malik, Jayanti Tokkas and Sneh Goyal, 2012. Microbial Pigments. International Journal of Microbial Resource Technology, pp 361-365.

[4] Poorniammal, Parthiban, Gunasekaran, Murugesan \& Thilagavathi, 2013. Natural dye production from Thermomyces sp. fungi for textile application. Indian journal of Fibre \& Textaile Research, vol.38, 276-279.

[5] Gargi Goswami, Surabhi Chaudhuri and Debjani Dutta, 2010. Effect of $\mathrm{pH}$ and temperature on pigment production from an isolated bacterium pp 1-6.

[6] Sharma, 2014. Understanding Biocolour, International Journal of Scientific \& Technology vol.3, pp 294 - 299.

[7] Joshi v.k, Devender Attri, Anju Bala and Shashi Bhushan, 2003. Microbial Pigments, Indian Journal of Biotechnology, vol.2, pp 362-369.

[8] Suman vikas bhat, sahara sayeed khan, Tawheed Amin, 2013. Isolation and characterization of pigment producing bacteria from various foods for their possible use of biocolours. International Journal of Recent Scientific Research, vol.3, pp 1605-1609.

[9] Chidambaram Kulandaisamy Venil, Zainul Akmar Zakaria, Wan Azlina Ahmada, 2013. Bacterial pigments and their applications. Process Biochemistry, pp 1065-1079. 
[10] Laurent dufosse, 2006. Microbial production of food grade pigments. Food Technol. Biotechnol, pp 313-321.

[11] Atalla, Mabrouk.M, Youssef and Mohamed, 2011. Production of textile reddish brown dyes by fungi. Malaysian journal of Microbiology, vol.7, pp 33-40.

[12] Madhura Nerurkar, Jyoti Vaidyanathan, Ravindra Adivarekara, Zarine Bhathena Langdana, 2013. Use of a natural dye from serratia marcescens subspecies marcescens in dyeing of textile fabrics, vol.1, pp 129-135.
[13] Oren A. 2002. Diversity of halophilic microorganisms Environments, Phylogeny, Physiology,and application. Journal of Industrial Microbiology and Biotechnology, vol. 28, 56-63.

[14] Parekh S, Vinci V, Strobel RJ, 2005. Improvement of microbial strains and fermentation processes. Application of Microbial Biotechnology, 287-301. 